\title{
Relation between job strain and myocardial infarction: a case-control study
}

\author{
Bo Netterstrøm, Finn E Nielsen, Tage S Kristensen, Elsa Bach, Lars Møller
}

Clinic of Occupational Medicine, Hillerød Hospital and Clinic of Occupational Medicine, State University Hospital, Copenhagen, Denmark B Netterstrøm

Department of Cardiology, Gentofte University Hospital and Department of Cardiology, Herlev University Hospital, Copenhagen, Denmark F E Nielsen

National Institute of Occupational Health, Copenhagen, Denmark T S Kristensen

E Bach

Department of Public Health, University of Copenhagen, Denmark L Møller

Correspondance to: Dr Bo Netterstrøm, Clinic of Occupational Medicine, Hillerød Hospital, DK 3400 Hillerød, Denmark.

Telephone 004548293531; fax 004548294713; email: bone@fa.dk

Accepted 30 November 1998

\begin{abstract}
Objectives-To study the influence of different job related and socioeconomic factors for development of myocardial infarction (MI).

Method-The study was a case-control study of 76 male wage earners who had been admitted to hospital with MI. As a control group 176 male wage earners not admitted to hospital who were residents of the same county were used. Both groups were interviewed with an extensive questionnaire on job related conditions. Several indices on job related psychosocial factors were established in accordance with Karasek's job strain model as well as the extension of the model, the isostrain model.
\end{abstract}

Results-The most significant findings were consistent with Karasek's job strain model in that men with a high degree of demand combined with a low degree of control at work had a significantly increased odds ratio (OR) $\mathbf{9 5 \%}$ confidence interval (95\% CI) of 2.1 (1.2 to 3.8) for MI after adjustment for age compared with men with a low degree of demand and a high degree of control at work. Further adjustment for smoking, socioeconomic status, employment sector, job category, and social network did not affect the OR substantially (OR 2.3 (1.2 to 4.4$)$ ). Other factors significantly associated to $\mathrm{MI}$ were job category ( blue collar workers $v$ white collar workers, OR 2.8 (1.6 to 5.8)), and employment sector (private $v$ public, $\mathrm{OR}$ 3.1 (1.8 to 6.1)).

Conclusions-Thus, the study confirmed the job strain model as well as the well known association between socioeconomic status and risk of MI, whereas the finding of an increased risk among employees in the private sector has not previously been described.

(Occup Environ Med 1999;56:339-342)

Keywords: myocardial infarction; job strain; casecontrol study; employment grade; job category; social network

Since Karasek in 1979 introduced the demandcontrol model ${ }^{1}$ several studies have shown an association between ischaemic heart disease (IHD) and job strain. According to the model high job strain (the combination of high psychological demands and low influence at work) leads to psychological strain and increased risk of cardiovascular disease. ${ }^{2}$ The model has been supplemented with a third dimension, social support, by Johnson and Hall. ${ }^{3}$ Publications on job strain and cardiovascular disease has been reviewed by Schnall et $a l,{ }^{4}$ Kristensen, ${ }^{5}$ and by Theorell and Karasek. ${ }^{6}$ The main conclusions are that most studies have supported the job strain hypothesis, but also that several theoretical and methodological issues have to be considered in future studies. One of the critical questions is the relation between social status and job strain. It has been claimed that job strain is simply a proxy measure for social status, which in many studies has been shown to be closely related to the development of IHD.

Earlier Danish studies have been contradictory. In a case control study Sihm et at found a significantly increased risk of IHD among men with high job strain. Suadicani et $a l^{9}$ investigated the topic in a prospective study of men above 55 years of age but found no association between job strain and risk of IHD. Netterstrøm et $a l^{10}$ analysed the association between job strain and cardiovascular risk factors in a cross sectional study of 1209 employees but found no clear trend of an increased risk among employees in high strain jobs. In this article we report on the results of a case-control study of wage earners admitted to hospital with acute myocardial infarction (MI) with wage earners not admitted to hospital as a control group.

\section{Methods}

PATIENTS

The cases were consequtive patients with MI admitted to the Department of Cardiology, Herlev University Hospital, from 1 January 1991 to 31 December 1992 and the department of Cardiology, Gentofte University Hospital situated in Copenhagen County, from 1 September 1991 to 31 December 1992. The criteria for MI were severe chest discomfort or electrocardiographic signs of MI accompanied by increased creatine phosphokinase to at least twice the normal upper limit.

The criteria for inclusion were that the participants had to be wage earners currently in employment and under 60 years of age at the time of the inclusion. Cases were interviewed by a nurse or doctor in the coronary care unit in the days after the diagnosis of MI. The response rate was $100 \%$.

Due to the relatively few women the final analysis only includes the 76 men. Their mean age was 52.5 years ( 31 were $40-49$ years old, 45 were 50-59 years old).

\section{CONTROL GROUP}

The control group consisted of 176 men, who in 1990 participated in a survey of work environment factors in which Danes in active 
Table 1 fob characteristics among 76 cases with myocardial infarction admitted to hospital and 176 male controls

\begin{tabular}{|c|c|c|c|}
\hline & Cases \% & Controls \% & p Value \\
\hline \multicolumn{4}{|l|}{ Educational level: } \\
\hline Unskilled or $<2$ y vocational training & 34 & 15 & 0.004 \\
\hline Skilled worker & 43 & 44 & 0.09 \\
\hline Intermediate education & 9 & 17 & 0.09 \\
\hline Academic & 14 & 22 & 0.12 \\
\hline \multicolumn{4}{|l|}{ Job: } \\
\hline High level white collar worker & 36 & 60 & 0.001 \\
\hline Low level white collar worker & 8 & 11 & 0.80 \\
\hline Skilled worker & 22 & 14 & 0.10 \\
\hline Unskilled worker & 34 & 14 & 0.003 \\
\hline Working hours a week $>37 \mathrm{~h}$ & 43 & 35 & 0.09 \\
\hline Extra source of income & 8 & 8 & 0.92 \\
\hline$\geqslant 10 \mathrm{y}$ in the same job & 63 & 69 & 0.71 \\
\hline Unemployed during the past $3 \mathrm{y}$ & 4 & 4 & 0.91 \\
\hline Employees in the company $(\mathrm{n}<50)$ & 33 & 23 & 0.09 \\
\hline Employed in the private sector & 76 & 53 & 0.004 \\
\hline Shift work & 16 & 14 & 0.33 \\
\hline Mode of payment: bonus, provision, etc & 9 & 8 & 0.85 \\
\hline Supplementary education within the past $3 \mathrm{y}$ & 41 & 52 & 0.25 \\
\hline
\end{tabular}

employment were interviewed by telephone. The questionnaire used was the same as the one used among the MI patients.

That survey was carried out by the National Institute of Occupational Health and the Institute of Social Research in $1990 .{ }^{11}$ The survey was carried out on a representative random sample of the Danish population in which 8664 people between 19 and 59 years of age participated. In the data material only those respondents $(n=5940)$ who were working as wage earners at the time of the interview, or had been so within the past 2 months, were included. The response rate was $90 \%$. The control group for the present study was selected on the basis of place of residence, sex, and age, in so far as they had to live in Copenhagen County as did the patients and their age was in the same range as the cases. We selected all male respondents in the age group 40-59 years as controls. This group did not have the same age distribution as the patients. Further control for age was done in the analyses. In this way 176 men (102 men between 40 and 49 years and 74 between 50 and 59 years old, mean 49.4 years) constituted the control group.

ANALYSIS

The data from the cases with MI were entered directly into the SPSS database containing the data from the control group.
Data on psychosocial work environment factors were analysed so that every answer to the questions referred to in table 2 was given a value $\geqslant 1$. The value increased relative to an increasing degree of negative content in the answer category in accordance with Karasek's job strain model. The values within each category of questions were then added (compare with table 2). In this way each index consisted of the sum of points for each answer category. Indices for skill discretion (Cronbach's $\alpha=0.65)$, decision authority $(\alpha=0.81)$, demands $(\alpha=0.51)$, and social network at the work place $(\alpha=0.55)$ were constructed. The indices for skill discretion and decision authority were combined into an index for decision latitude. This index was then dichotomised and a strain variable constructed according to Karasek's demand-control (job strain) model. In accordance with the job strain model the four groups were defined as follows: strain was high demands and low decision latitude; active was high demands and high decision latitude; passive was low demands and low decision latitude; relaxed was low demands and high decision latitude. The variables on social relations and support at the place of work were converted into an index for social network.

Data from both the cases and the control group were transferred to the statistics programme EPI-info for bivariate analyses. $\chi^{2}$ Tests were used as tests of significance with 0.05 as the significance level. For multivariate analyses (logistic regression) SPSS was used. The variables used in the logistic regression model were age, job strain, social network, smoking habits, and all items shown in table 1 . All variables were entered into the model (excluding stepwise) with $95 \%$ significance level in a backwards procedure.

\section{Results}

Table 1 outlines the employment conditions of the cases and the control group. Most of the cases had a low level of education. Thus, significantly more cases (34\%) than controls $(15 \%)$ had $<2$ years of vocational training. The proportion of skilled workers was equal in the two groups, but there were relatively more with an academic education among controls.

Table 2 Prevalence of psychosocial job characteristics among 76 cases admitted to hospital with myocardial infarction and 176 controls

\begin{tabular}{|c|c|c|c|}
\hline & Cases \% & Controls \% & $O R(95 \% C I)$ \\
\hline \multicolumn{4}{|l|}{ Skill discretion: } \\
\hline Repeat the same working operations & 47.4 & 46.6 & $1.03(0.6$ to 1.8$)$ \\
\hline Few possibilities to learn new things & 51.3 & 55.1 & $0.86(0.5$ to 1.5$)$ \\
\hline Low degree of varied work & 53.9 & 38.5 & $1.86(1.1$ to 3.2$)$ \\
\hline \multicolumn{4}{|l|}{ Decision authority: } \\
\hline Low degree of influence on work pace & 40.8 & 29.5 & $1.64(1.1$ to 3.0$)$ \\
\hline Low influence on planning of work & 44.7 & 33.5 & $1.61(0.9$ to 2.8$)$ \\
\hline Low degree of influence on solving of problems & 59.2 & 54.5 & $1.21(0.7$ to 2.1$)$ \\
\hline \multicolumn{4}{|l|}{ Demands at the workplace: } \\
\hline \multicolumn{4}{|c|}{ The amount of work is often so great that there is no time to } \\
\hline The work needs attention all the time & 64.5 & 47.2 & $2.03(1.2$ to 3.5$)$ \\
\hline The work is physically demanding & 65.8 & 54.0 & $1.64(0.9$ to 2.9$)$ \\
\hline Risks for others in case of mistakes & 30.3 & 23.9 & $1.38(0.8$ to 2.5$)$ \\
\hline \multicolumn{4}{|l|}{ Support at the workplace: } \\
\hline Not always possibility for advice and help & 38.2 & 33.5 & $1.22(0.7$ to 2.1$)$ \\
\hline Usually not praised by employer & 42.1 & 47.7 & $0.80(0.5$ to 1.4$)$ \\
\hline \multicolumn{4}{|l|}{ Social relations: } \\
\hline Isolated work often & 53.9 & 59.1 & $0.81(0.5$ to 1.4$)$ \\
\hline Low possibilities to speak with colleagues & 53.9 & 56.3 & $0.91(0.5$ to 1.5$)$ \\
\hline
\end{tabular}


Table 3 Prevalence of scores on the psychosocial indices among 76 cases with myocardial infarction and 176 controls

\begin{tabular}{lllll}
\hline Index & Cases $\%$ & Controls $\%$ & OR & $95 \%$ CI \\
\hline Low skill discretion & 25.0 & 17.7 & 1.50 & 0.8 to 2.9 \\
Low decision authority & 35.5 & 29.7 & 1.28 & 0.7 to 2.3 \\
Low decision latitude & 42.1 & 37.2 & 1.21 & 0.7 to 2.1 \\
High demands & 39.5 & 28.6 & 1.62 & 0.9 to 2.8 \\
Poor social network & 36.8 & 42.3 & 0.81 & 0.5 to 1.4 \\
\hline
\end{tabular}

Table 4 First and final model (backwards approach, includes all variables with $p<0.05$ ) of logistic regression analysis of the association between myocardial infarction and age, job strain, smoking habits, social network, employment sector, and job category

\begin{tabular}{lll}
\hline & Enter model OR $(95 \%$ CI) & Final model OR $(95 \%$ CI) \\
\hline Age & $1.06(1.0$ to 1.1$)$ & $1.06(1.0$ to 1.1$)$ \\
Strain $v$ relaxed & $2.15(1.1$ to 4.3$)$ & $2.31(1.2$ to 4.6$)$ \\
Active $v$ relaxed & $0.57(0.3$ to 1.0$)$ & $0.56(0.3$ to 1.0$)$ \\
Passive $v$ relaxed & $0.88(0.5$ to 1.5$)$ & $0.89(0.5$ to 1.5$)$ \\
Private $v$ public employee & $3.30(1.9$ to 6.5$)$ & $3.12(1.8$ to 6.1$)$ \\
Blue collar or white collar & $2.92(1.7$ to 5.9$)$ & $2.84(1.6$ to 5.8$)$ \\
Smoking & $1.10(0.6$ to 1.9$)$ & \\
Social network & $0.67(0.3$ to 1.1$)$ & \\
\hline
\end{tabular}

There were significantly fewer high level white collar workers and more unskilled workers among cases. Furthermore, a larger proportion of the cases were employed in the private sector.

The questions regarding psychosocial working conditions were classified according to the five main job characteristics shown in table 2 .

Significantly more cases indicated that they were in a job with a low degree of varied work and a low degree of influence on the work pace.

Low influence on planning of work were reported slightly more often among cases than controls $(p<0.1)$. For demands, only the indication that the work needs attention all the time reached significance, although there was a tendency that all demand items were reported more often among cases. There were no differences between the groups for social support or social relations at the workplace.

In table 3 the five indices on psychosocial work environment factors were dichotomised and the two groups compared. None of the differences were significant but there was a tendency towards lower decision latitude and higher demands among the cases.

Table 4 shows the enter model with relevant variable forced into the model and the final model in a backwards logistic regression analysis. The table shows that the strain group had a significantly increased risk of MI compared with the reference category (the relaxed group). The active group, on the other hand, had a borderline decreased risk. Job strain considered as one variable, was not significant $(p=0.09)$. This was mainly due to the fact that the association between job strain and MI was slightly U shaped with lower odds ratios (OR) values among people with middling strain (active and passive groups). Private employees had more than three times the risk of public employees after control for the other factors, and blue collar workers had almost three times the risk of white collar workers.

The results of multiple logistic regression analyses with stepwise adjustment for the association between job strain and MI for other relevant variables are shown in table 5 . The crude OR for the job strain group compared with the relaxed group was 2.1. Controlling for age did not change this figure. After additional control for smoking the OR decreased but was still significant. After control for other factors the OR was 2.3.

When the analysis was restricted to white collar workers the OR remained almost the same: strain $v$ relaxed 2.7 (1.0 to 6.8 ), active $v$ relaxed $0.4(0.2$ to 1.2$)$ and passive $v$ relaxed 0.9 (0.4 to 1.8), whereas OR for being employed in the private sector increased to 5.0 (1.6 to 10.1). Restriction to only blue collar workers resulted in non-significant results. The highest ORs were for employment sector (2.7 $(0.9$ to 8.2$))$ and strain $v$ relaxed $(2.0$ (0.6 to $6.1))$.

\section{Discussion}

In case-control studies information bias is always an issue. It might be argued that patients with MI would tend to report more stressful factors than controls. This question has been elucidated in different ways in the scientific literature. In a recent case-control study Theorell et $a l^{12}$ used two different methods for the assessment of demands and decision latitude: self reports (as in this study) and average values for specific occupations. These two methods yielded similar results, and there was no tendency for the cases to exaggerate exposures. In the present study we found that the controls in some cases complained more than the cases. For example, the controls reported more isolation, fewer possibilities for speaking with colleagues, and were more often not praised by the employer. These results indicate that the cases did not show a systematic tendency to overreport compared with the controls. The differentiated pattern of replies to the different questions in the questionnaire does not support the hypothesis of a systematic information bias.

We do not consider selection bias to be an issue in this study. In Denmark almost all cases of MI are admitted to public hospitals, and the response rate among cases was $100 \%$. Among controls the response rate was also very high, $90 \%$.

Table 5 Logistic regression analyses of the relation between myocardial infarction and job strain adjusted for different possible confounders

\begin{tabular}{lllll}
\hline & fob strain groups & & \\
\cline { 2 - 6 } Adjustment factor & $\begin{array}{l}\text { Strain OR } \\
\text { (95\% CI) }\end{array}$ & $\begin{array}{l}\text { Passive OR } \\
\text { (95\% CI) }\end{array}$ & $\begin{array}{l}\text { Active OR } \\
\text { (95\% CI) }\end{array}$ & $\begin{array}{c}\text { Relaxed } \\
\text { OR }\end{array}$ \\
\hline $\begin{array}{llll}\text { Age } \\
\text { Age, employment sector, and job category }\end{array}$ & $2.1(1.2$ to 3.8$)$ & $0.8(0.5$ to 1.3$)$ & $0.7(0.4$ to 1.1$)$ & 1 \\
$\begin{array}{l}\text { Age, employment sector, job category, and smoking } \\
\text { Age, employment sector, job category, smoking, and }\end{array}$ & $2.3(1.2$ to 4.3$)$ & $0.9(0.5$ to 1.5$)$ & $0.5(0.3$ to 0.9$)$ & 1 \\
$\quad$ social network & $1.9(1.0$ to 3.8$)$ & $0.9(0.5$ to 1.6$)$ & $0.6(0.3$ to 1.0$)$ & 1 \\
\hline
\end{tabular}


Another question is the existence of confounding factors. We controlled for age, smoking, social status, and other psychosocial factors but not for cholesterol and blood pressure. It is a general finding in publications on job strain that controlling for cholesterol and blood pressure usually changes the estimates of relative risk to a minor degree. ${ }^{4}$ This was clearly confirmed in the recent Swedish study by Theorell et $a l^{12}$ in which the risk estimates remained almost the same after controlling for smoking, low density lipoprotein/high density lipoprotein ratio, history of hypertension, and history of chest pain. In a Danish study we found no association between job strain and cholesterol, triglycerides, or blood pressure..$^{10}$ In another Danish study from the Copenhagen County these factors were unrelated to socioeconomic status. ${ }^{13}$ These findings from other studies give us reason to think that our risk estimates would not have changed substantially if it had been possible for us to obtain data on the physiological risk factors in our sample.

Six case-control studies on job strain and IHD have been reported. One Danish study by Sihm et $a l^{8}$ and one Swedish ${ }^{14}{ }^{15}$ yielded risk ratios (RRs) of 2.8-4.0 for the relation between $\mathrm{MI}$ and job strain. Four other Swedish studies found $\mathrm{RR}$ values around 1.3. ${ }^{16-19}$ An American case-control study among patients undergoing coronary angiography ${ }^{20}$ found no association between job strain and the presence of coronary disease or with long term outcome. This study is, however, not comparable with the other studies mentioned as all participants in the study base were patients.

Thus, the present study supports the consistent positive findings of the previous case control studies with healthy controls. This adds to the overall support for the hypothesis of a causal association between job strain and IHD. ${ }^{61}$ The negative studies of job strain and cardiovascular disease reported have been adequately discussed earlier. ${ }^{4-6}$

The finding that men with both high control and high demands had a decreased risk of MI is in agreement with other studies, ${ }^{22} 23$ and might reflect that the control component in the job strain model is a stronger predictor of IHD than high demands. ${ }^{12}$

Our study also confirmed the well known association between socioeconomic status and $\mathrm{MI},{ }^{7}$ and our results indicate that this association cannot be explained by job strain or other psychosocial factors included in the study.
Finally, we found that private employees have three times the risk of MI than public employees after control for job strain, social class, smoking, social network, and age. We have no explanation for this unexpected finding and look forward to other studies on the topic.

1 Karasek RA. Job demands, job decision latitude and mental train: implications for job redesign. Administrative Science Quarterly 1979;24:285-308.

2 Karasek RA, Russell RS, Theorell T. Physiology of stress and regeneration in job related cardiovascular illness. $f$ Hum Stress 1982;8:29-42.

3 Johnson JV, Hall EM. Job strain, work place social support and cardiovascular disease: a cross-sectional study of a random sample of the Swedish working population. Am f Public Health 1988;78:1336-42.

4 Schnall PL, Landsbergis PA, Baker D. Job strain and cardiovascular disease. Ann Rev Public Health 1994;15: 381-411.

5 Kristensen TS. The demand-control-support model: methodological challenges for future research. Stress Med 1995; 11:17-26

6 Theorell T, Karasek RA. Current issues relating to psychosocial job strain and cardiovascular disease research. $\mathcal{f}$ Occup Health Psychol 1996;1:9-26.

7 Kaplan GA, Keil JE. Socioeconomic factors and cardiovascular disease: a review of the literature. Circulation 1993;88: 1973-98.

8 Sihm I, Dehlholm G, Hansen ES, et al. The psychosocial work environment of younger men surviving acute myocardial infarction. Eur Heart $\mathcal{7}$ 1991;12:203-9.

9 Suadicani P, Hein HO, Gyntelberg F. Are social inequalities as associated with the risk of ischaemic heart disease a result of psychosocial working conditions? Atherosclerosis 1993;101:165-75.

10 Netterstrøm B, Kristensen TS, Damsgaard M T, et al. Job strain and cardiovascular risk factors: a cross sectional tudy of employed Danish men and women. Br f Ind Med 1991;48:684-9.

11 Nord-Larsen M, Ørhede E, Nielsen J, et al. Lønmodtagernes arbejdsmiljø 1990. Copenhagen: Arbejdsmiljøfondet, 1992 .

12 Theorell T, Tsutsumi A, Hallquist J, et al. Decision latitude, ob strain, and myocardial infarction. Am f Public Health 1998;88:382-8.

13 Møller L, Kristensen TS, Hollnagel H. Social class and cardiovascular risk factors in Danish men. Scand $\mathcal{F}$ Soc Med 1991;19:116-26.

14 Ahlbom A, Karasek R, Theorell T. Psykosocial arbetskrav och risk för hjärt-kärldöd. Läkartidn 1980;77:4243-5.

15 Karasek R A, Baker D, Marxer F, et al. Job decision latitude ob demands and cardiovascular disease. A prospective study of Swedish men. Am f Public Health 1981:71:694705 .

16 Alfredsson L, Karasek R, Theorell T. Myocardial infarction risk and psychosocial work environment: an analysis of the male Swedish working force. Soc Sci Med 1982;16:463-7.

17 Alfredsson L, Theorell T. Job characteristics of occupations and myocardial infarction risk: effect of possible confounding factors. Soc Sci Med 1983;17:1497-503.

18 Theorell T, Hamsten A, de Faire U, et al. Psychosocial work conditions before myocardial infarction in young men. Int $\mathcal{F}$ Cardiol 1987;15:33-46.

19 Hammar N, Alfredsson L, Theorell T. Job characteristics and the incidence of myocardial infarction. Int $\mathcal{F}$ Epidemiol 1994:23:277-84

20 Hlatky MA, Lam LC, Lee KL, et al. Job strain and the prevalence and outcome of coronary heart disease. Circulation 1995;92:327-33.

21 Karasek R, Theorell T. Healthy work. New York, Basic Books, 1990.

22 Steenland K, Johnson JV, Nowlin S. A follow up study of job strain and heart disease among males in the NHANES1 population. Am F Ind Med 1997;31:256-60.

23 Hammar N, Alfredsson, Johnson JV. Job strain, social support at work, and incidence of myocardial infarction. Occup Environ Med 1998;55:548-53. 